CLINICAL PRACTICE IN INFECTIOUS DISEASES

By E. H. R. HARRIES, M.D., F.R.C.P., D.P.H., and M. Mitman, M.D., M.R.C.P., D.P.H., D.M.R.E. 2nd. Edition. E. \& S. Livingstone, Edinburgh. 1944. 22s. 6d. net.

The second edition of this book will be much more useful to the qualified practitioner than the first. It is up-to-date, and embodies all the main advances in thought and practice of the last four or five years. References are now given in full.

More attention is paid to the historical aspect, to epidemiology and immunology than in the former edition. The new chapter on chemotherapy is concise, clear and fully informative. As might be expected, the problems of hospital cross-infections and their control are fully set out and practical procedures are discussed. A goodly number of diagrams and tables make the subject-matter very clear. The experienced clinical reader may miss the stimulation, the readableness that derives from the use of personal anecdote or original observation. The presentation is somewhat formal and rigid. He will find, however, in this book a mine of information, a guide to modern thought on fevers, and a work of reference which is likely to retain its usefulness for some considerable time to come.

\section{THE DIABETIC LIFE}

By R. D. LAwrence, M.A., M.D., F.R.C.P. 13th Edition. J. \& A. Churchill, London. 1944. Price Ios. 6d.

The thirteenth edition of this well-known book will be welcomed by diabetics and their doctors. It is very comprehensive, and from the point of view of the lay patient this might be a disadvantage. Certainly the subject must have appeared more simple to the readers of the first edition. Nevertheless, the subject-matter is clearly divided and classified, and deals simply and effectively with all aspects of diabetes.

The story of the discovery of insulin will always remain one of the most fascinating chapters in medicine, no matter how many times it is retold. The fallacy of the old saying that "fats are burnt in the furnace of the carbohydrates" is exploded by experimental evidence, which shows that perfused muscles of depancreatised animals can oxidise ketones as readily as those of normal animals, and Lawrence rightly points out that ketones appear in diabetics because abnormal amounts of fats are broken down, since unutilised carbohydrates cannot supply energy requirements. It is therefore an exaggeration of a normal process.

The diagnostic table on page 29, differentiating diabetic coma and insulin coma, is a valuable one, especially as the incidence of insulin coma appears to be on the increase nowadays.

The advantages and limitations of Zinc Protamine Insulin are well discussed, and its use in combination with simple insulin illustrated. Globin insulin is hardly mentioned, and its use is not generally favoured by the writer, although it is of value in some cases.

The food values and tables are excellent, and invaluable for practical purposes, and the whole production is of high quality.
FAMILIAL NONREAGINIC FOOD ALLERGY

By Arthur F. CocA, M.D., Medical Director Lederle Laboratories. Charles C. Thomas, Springfield, U.S.A.; Baillière, Tindall \& Cox, London. 1943. Price r6s. 6d.

Some persons complain of various usually vague symptoms repeatedly following the ingestion of certain foods. Coca classes these as cases of familial non-reaginic food allergy because (a) a hereditary influence to this type of reaction appears to exist quite apart from any ordinary allergic predisposition, and $(b)$ in most cases the skin tests have proved negative because there do not appear to be any specific reagins or allergens in the blood.

Following the ingestion of such causative foods, Coca has observed an acceleration of the pulse consisting of (a) a rapidly alternating tachycardia and remission of the high pulse rate; (b) a latent period, the food may be taken for a day or two before the accelerated pulse was observed, and $(c)$ the reaction may continue after the allergic food is discontinued.

The symptoms experienced seem to lie outside the realm of those usually considered allergicnervousness, dizziness, physical tiredness and irritability; vessels of aluminium or stainless steel should be avoided as a sensitivity to such metals is suggested, and substances other than foods often cause identical reactions. As Shakespeare says, "Confusion now hath made his masterpiece."

\section{TEXTBOOK OF HISTOLOGY 3rd Edition}

By Evelyn E. Hewer, D.Sc.(Lond,). Wm. -Heinemann Medical Books Ltd. I944. Price I7s. 6d.

Both the author and the publisher are to be congratulated on producing the third edition of this excellent textbook within seven years of its initial appearance. Designed primarily for medical students, it more than fulfils its purpose, for the subject matter is well presented in a most readable form, aided by very fine illustrations and helpful explanatory diagrams of some of the microphotographs. The format, also, is of a very high standard.

We feel that the present-day preclinical student is indeed lucky to have such a stimulating book on histology for, although not generally realised by the. student at the time, histology is a very important subject, a proper knowledge of which proves invaluable in later studies.

But the medical student should not be the only reader of this book. It should be studied by all those sitting for the higher examinations before they set off to master the intricacies of modern patbology; and the clinician who likes to examine his own clinical pathological specimens would have his memory of not only the "fixed" tissues but also of the normal physiological variations sharpened, much to his advantage. To the general practitioner, perusal would bring much light and not a little interest in his everyday medical problems.

This book is strongly recommended. 